\title{
Aa. Vv., La Poésie populaire en France au XIX siècle: théories, pratiques et réception
}

\section{Nicolas Courtinat}

\section{(2) OpenEdition}

\section{Journals}

\section{Édition électronique}

URL : http://journals.openedition.org/studifrancesi/8280

DOI : ERREUR PDO dans /localdata/www-bin/Core/Core/Db/Db.class.php L.34 : SQLSTATE[HYO00]

[2006] MySQL server has gone away

ISSN : 2421-5856

\section{Éditeur}

Rosenberg \& Sellier

\section{Édition imprimée}

Date de publication : 1 mai 2009

Pagination : 180-181

ISSN : 0039-2944

\section{Référence électronique}

Nicolas Courtinat, «Aa. Vv., La Poésie populaire en France au xix siècle: théories, pratiques et réception », Studi Francesi [En ligne], 157 (LIII | I) | 2009, mis en ligne le 30 novembre 2015, consulté le 07 janvier 2021. URL : http://journals.openedition.org/studifrancesi/8280 ; DOI : https://doi.org/ERREUR PDO dans /localdata/www-bin/Core/Core/Db/Db.class.php L.34 : SQLSTATE[HY000] [2006] MySQL server has gone away

Ce document a été généré automatiquement le 7 janvier 2021.

\section{(c)}

Studi Francesi è distribuita con Licenza Creative Commons Attribuzione - Non commerciale - Non opere derivate 4.0 Internazionale. 


\title{
Aa. Vv., La Poésie populaire en France au XIX ${ }^{\mathrm{e}}$ siècle: théories, pratiques et réception
}

\author{
Nicolas Courtinat
}

\section{RÉFÉRENCE}

La Poésie populaire en France au XIX siècle: théories, pratiques et réception, sous la direction d'Hélène MILLOT, Nathalie VINCENT-MUNNIA, Marie-Claude SCHAPIRA et Michèle FONTANA, Tusson, Éditions du Lérot, 2005, pp. 768.

Dans le vaste domaine de la «littérature populaire», exploré au cours des dernières décennies par de nombreux chercheurs, la poésie (au sens large du terme: poèmes, mais aussi chansons) a souvent été délaissée au profit du roman. Rédigé par une quinzaine de chercheurs appartenant pour la plupart à l'unité de recherche «LIRE» du CNRS, cet imposant ouvrage se propose de combler cette lacune. L'ambition du livre s'affiche dès son titre: il s'agit non seulement d'étudier les formes et les thèmes de cette poésie, mais aussi les discours théoriques qui se sont développés sur elle et autour d'elle, ainsi que leur réception, notamment par les écrivains de renom qui, pour des raisons diverses, se sont intéressés à elle. Chacun se doute que, dans l'immense production de poésies ou de chansons populaires qu'a connue le $\mathrm{xIX}^{\mathrm{e}}$ siècle, tout ne mérite pas d'être célébré. Or, comme le souligne avec justesse l'introduction de l'ouvrage, une histoire de la littérature digne de ce nom «doit prendre en compte tous les modes d'expression, légitimés ou non, c'est-à-dire également ceux qui ne reçoivent pas l'onction de la littérarité» (p. 18).

2 La première partie de l'ouvrage traite de l'essor de cette «poésie populaire», que les auteurs situent entre 1830 et 1850 . Tandis que Souvestre et La Villemarqué font connaître les genres populaires bretons (l'histoire est bien connue), un énorme corpus de poésie populaire se forme petit à petit, nourri entre autres par les chansons de 
compagnonnage et les chansons des goguettes. Les journaux les impriment, des anthologies et des recueils personnels sont publiés dès cette époque. Beaucoup de ces chansons constituent de véritables professions de foi républicaines (p. 123). Aussi fontelles l'objet d'une surveillance policière et administrative («La chanson peut infecter jusqu'à l'air qu'on respire», lit-on sous la plume du procureur Marchangy, p. 93), qui débouche parfois sur des poursuites et des condamnations. Cela n'empêche pas certains écrivains célèbres d'offrir leur protection aux auteurs de poésies populaires, non sans excès ni arrière-pensées. L'ouvrage montre comment Lamartine a littéralement "pris en ôtage» Reine Garde, incarnation à ses yeux du «bon peuple», provincial, domestique, résigné: à l'évidence, le poète l'a utilisée pour cautionner son propre discours sur le peuple (tel en tout cas qu'il se le représentait) et la littérature populaire (p. 154). Sand, de son côté, aide beaucoup Poncy, et même trop, au point de «pygmalionniser sans vergogne» son protégé (p.394). Ces deux exemples montrent en tout cas comment certains grands écrivains $\mathrm{du} \mathrm{xIX}^{\mathrm{e}}$ siècle ont voulu exercer une véritable tutelle intellectuelle et morale sur des poètes dont ils percevaient l'importance en ces temps de bouleversement social.

3 La deuxième partie, qui traite des «pratiques» de cette poésie, est peut-être la plus intéressante. Elle s'ouvre sur une surprise: au niveau formel, cette poésie demeure très conformiste et largement dépendante des modèles prosodiques, classiques ou romantiques, pratiqués en son temps. Les modèles (à la fois poétiques et politiques) sont Lamartine, Marceline Desbordes-Valmore, Victor Hugo (on imite «Les Djinns»: voir p. 209). Les formes utilisées sont l'ode, l'élégie, l'épître, les stances, et même la fable (p. 195). L'analyse des œuvres montre l'immense variété de ces «pratiques». La poésie de circonstance côtoie les poèmes légers ou grivois et les chansons à boire. Le lyrisme sentimental, avec ses «Ô vous...!» aussi convenus qu'exaspérants (p. 239), le lyrisme de la nature (les zéphirs, les «doux printemps», les «vents mélancoliques» font toujours fortune!) se développent au moins autant que le lyrisme social, plus attendu (appels à la fraternité, glorification du travail nourrie de réalisme ouvrier, sacralisation du peupleprophète...). La critique sociale, féroce, vindicative, perce ici et là. Gustave Leroy s'attaque au «fainéant millionnaire» (p. 314), Savinien Lapointe oppose «l'entresol», où se trouve l'appartement somptueux du bourgeois, au «grenier» où règnent «la faim et les sanglots» (p. 283). La littérature se fait ici action, avec ses exhortations, ses appels passionnés à la révolte. Cette partie s'achève sur trois monographies de trois poètes emblématiques de cette période effervescente: Savinien Lapointe, dont la poésie est plus sociale que politique; le saint-simonien Louis Vinçard, fondateur du premier journal populaire à publier de la poésie; l'agenais Jacques Boé, dit Jasmin, le «troubadour du peuple», très attaché à sa langue régionale. C'est une poésie très riche qui se dessine finalement sous nos yeux, maniant à la fois le lyrisme, le réalisme, la caricature, l'attaque frontale. Il manque seulement à cette excellente partie une analyse plus méthodique de l'imagerie de cette poésie: le sang qui trace la route, le grain qui germe, les trônes qui tombent, l'arbre du capital que l'on ronge petit à petit sont autant de leitmotive sur lesquels il aurait été utile d'insister davantage.

4 La partie suivante s'intéresse à la théorisation et à la réception de cette poésie. Tandis que certains y voient l'émanation d'une "populace» dépravée et dangereuse, d'autres veulent y lire la grandeur d'un «peuple-nation intégré dans l'unité patriotique et nationale» (p. 383). Là encore, l'ouvrage insiste judicieusement sur quelques parcours individuels. Hugo, par exemple, verra dans cette poésie comme un relais de sa propre révolte contre le régime de Napoléon III et la valorisera pour la vérité et l'humanité 
dont elle est porteuse (p.423). Baudelaire évoluera dans le sens contraire: le projet aristocratique des Fleurs du Mal l'amènera à faire son deuil de cette poésie qu'il jugera finalement très médiocre (p. 432). Quant aux écrivains «populaires» eux-mêmes, ils n'omettent point de sacraliser la mission du poète qui parle en leur nom, et dont la grandeur est de se mettre au service de sa classe (p. 463).

Beaucoup plus brève (ce qui n'est pas sans compromettre quelque peu l'équilibre de l'ouvrage), la dernière partie étudie l'évolution de cette poésie à partir de 1850 . Critiquée, occultée ou instrumentalisée, la poésie populaire perd l'aura dont elle bénéficiait sous la Monarchie de Juillet. Elle se réduit progressivement à des formes de moins en moins subversives, voire carrément médiocres, comme ces «chansons populacières exploitant sans vergogne, dans un but mercantile, les clichés des basfonds» (p. 17). Une forme d'expression authentiquement populaire subsiste malgré tout dans les chansons de la Commune et les poèmes anarchistes de la Belle Époque, auxquelles cette partie consacre d'intéressants développements.

6 Dans chaque partie de l'ouvrage, les nombreuses citations permettent au lecteur de juger «sur pièces» cette poésie. Les bibliographies, primaire et secondaire, très riches (et qui auraient pu, compte tenu du sujet, intégrer quelques éléments discographiques) rendront de grands services aux chercheurs. Neuf, clair et savant, cet ouvrage forme un excellent ensemble sur un sujet qui manquait jusqu'à ce jour d'une synthèse. Un livre donc amené à devenir... populaire! 